\title{
INTERAÇÃO SOCIAL, IMAGENS E APRENDIZAGENS EM ARTE E EDUCAÇÃO INCLUSIVA*1
}

\author{
Prof. Dra. Neli Klix Freitas*2
}

Palavras-Chave: Arte e Educação Inclusiva; Formação de Professores; Necessidades Educativas Especiais; Aprendizagens

\section{RESUMO}

$\mathrm{O}$ artigo propõe-se a apresentar dados da pesquisa sobre o tema das Imagens, Desenhos e Significados em Educação Inclusiva, desenvolvida pela autora. $\mathrm{O}$ direito ao ensino regular tem possibilitado às crianças com necessidades educativas especiais e aos professores envolvidos nesse processo a busca de capacitação em várias áreas do conhecimento, desenvolvendo funções cognitivas e sociais. $\mathrm{O}$ resultados assinalam para categorias de análise que relacionam aprendizagens, formação humana, interação social e aceitação de diferenças, relevantes em arte e educação inclusiva.

\section{INTRODUÇÃO}

A educação inclusiva permite lançar o olhar para múltiplas direções.O que ocorre em nossos tempos é que alguns matizes de diferenças até aqui ignorados, ou ocultos tem sido repensados, pelo menos não negados, talvez porque a legislação tenha estabelecido critérios mais rigorosos, ou por outras razões. As diferentes formas e ritmos de aprendizagens devem ser vistas não como um atributo, ou como uma uma característica dos chamados de diferentes, mas como uma possibilidade de ampliar a compreensão acerca da intensidade da diversidade humana.

1 Projeto de Pesquisa:Imagens,Desenhos e Significados de Professores e Alunos com Necessidades Educativas Especiais, em Escolas com Educação Inclusiva. Centro de Artes - CEART

2 Prof. Coordenadora da Pesquisa- Depto.de Artes Visuais

3. Bolsistas PIC Janaí de Abreu Pereira e Fernanda Trentini Carneiro-CEART 
Essas e outras questões importantes emergiram em nossa pesquisa, tanto na consulta à literatura e à legislação, quanto na coleta de dados, na escuta e no convívio com os principais atores do processo de educação inclusiva: professores e, no caso da delimitação da pesquisa, alunos com necessidades educativas especiais.

\section{REVISÃO DA LITERATURA}

A visão do ensino sócio-inclusivo impõe a demolição dos discursos educacionais que excluem as diferenças. A fronteira que separa de forma nítida aqueles olhares que continuam pensando que o problema da educação escolar está na anormalidade, bem como daqueles que pensam o oposto: os que consideram a normalidade, a norma, o normal como o problema em questão é que deveria ser colocado sob suspeita. Trata-se de representações que se apresentam como científicas e acadêmicas, vigiando cada desvio, descrevendo cada detalhe das patologias, cada vestígio da normalidade, suspeitando de toda deficiência com a conhecida afirmação de que “algo está errado no sujeito, que possuir uma deficiência é um problema" (SKLIAR, 2003, p.18).

Essas considerações remetem-nos a lançar outros olhares, talvez menos vigilantes, que tenham de inverter a discussão fazendo do normal, da norma, o problema que deve ser colocado em questão.Esses olhares têm muito a oferecer à educação em geral, produzindo a desmistificação do normal, questionando os parâmetros instalados na pedagogia sobre o que deve ser correto (BERIAIN, 1996; MCLAREN,1997).

Se por um lado o acesso dos portadores de necessidades educativas especiais às escolas de ensino regular cresce a cada dia, por outro ainda são precárias as instalações físicas, a oferta de material didático-pedagógico adequado e a capacitação de professores, para efetivar uma educação inclusiva de qualidade.

Vygotsky, expoente do Sócio-Interacionismo postula que o professor deve ser um mediador entre o sujeito que aprende e o conhecimento. Mediar consiste nas ações de um agente intermediário em uma relação. Vygotsky trabalha com a noção de que a relação homemmundo não é uma relação direta, mas fundamentalmente mediada(VYGOTSKY, 1987). 
Nessa perspectiva não há espaço para a transmissão de conhecimentos sem a presença dos signos, dos símbolos e da cultura, considerados como agentes mediadores e ferramentasúteis no processo de aquisição do conhecimento.. Compete ao professor conhecer essa questão, para adequar posturas e métodos a um modelo que coincide com práticas educativas atualizadas. Com a educação inclusiva, a mediação adquire um caráter de grande importância,uma vez que situa três questões imprescindíveis ao processo de construção do conhecimento: o aluno, como o sujeito que aprende; o professor como mediador; a cultura , os signos como ferramentas a serem empregadas.O princípio que regula a dinâmica implícita nessa trama conceitual é a interação social. Trata-se de um modelo pertinente em tempos de educação inclusiva, onde a interação é o princípio essencial (VYGOTSKY, 1984).

Ao longo do processo de desenvolvimento,.o ser humano deixa de necessitar das marcas externas e passa a utilizar signos internos, isto é, representações mentais, que substituem os objetos do mundo real, o que é fundamental para o processamento de aprendizagens (VYGOTSKY, 1987;OLIVEIRA, 2001).

Desse modo, crianças com necessidades educativas especiais necessitam de ações mediadas, dos agentes mediadores, da postura de mediação do professor, sempre em interação com crianças sem necessidades educativas especiais. Na medida em que esse processo se consolida, alunos sem necessidades educativas especiais tornam-se também mediadores para seus colegas com necessidades educativas especiais, e a educação se reconfigura. Trata-se de novos tempos, que exigem outras posturas, nas quais a interação social é imprescindível. Mas, essa proposta carrega em seu bojo uma dinâmica de aceitação de diferenças, em uma postura ética solidária. Para serem inclusivas, as escolas devem modificar-se em suas estruturas de base, para assegurar uma educação de qualidade, que não pode prescindir de parcerias com a comunidade. Acima de tudo, a sociedade deve dirigir o olhar para essa questão, educando para o convívio com as diferenças.

\section{METODOLOGIA DA PESQUISA}

Foram participantes da pesquisa trinta e cinco professores com formação em Artes Visuais e com experiência atual em classes de escolas com educação inclusiva, bem como quinze alunos com diferentes necessidades educativas especiais: dislexia, deficiência auditiva, 
transtorno por déficit de atenção com hiperatividade, retardo mental, paralisia cerebral, síndrome do Down e autismo, todos inseridos em classes de escolas com educação inclusiva, totalizando dez escolas da cidade de Florianópolis.

Os professores responderam a um questionário e à técnica "cartas de quem gosta de escrever", que consiste em escrever uma carta a um professor que tenha sido significativo em sua formação.As crianças foram solicitadas a realizar desenhos, trabalhos com argila, massa de modelar, recorte e colagem, e a falar sobre seus trabalhos, adotando-se a técnica semelhante ao desenho-história. Cada criança realizou uma série de dez visualidades, ao longo de cinco encontros, todos coletados pela pesquisadora e pela bolsista nas próprias escolas, em salas de multimeios ou outras salas com as condições necessárias:silêncio, privacidade, iluminação,principalmente.Ao longo dessa etapa da pesquisa houve nova coleta de desenhos com as mesmas crianças que participaram no ano anterior, para evidenciar possíveis alterações nos desenhos.Foram coletados dados com mais cinco crianças.Todas elas, à medida em que desenhavam, foram também convidadas a falar sobre suas atividades,ou usar expressões corporais,bem como sinais.Com as crianças portadoras de deficiência auditiva houve a mediação de uma professora com domínio de Linguagem de Sinais.Todo o material foi registrado, através do uso de gravador e de fotografias, devidamente autorizadas pelas direções das escolas e pelos pais das crianças.

Os pais das crianças também foram entrevistados, antes do início da coleta de dados, solicitando-se a assinatura do termo de consentimento informado, de acordo com os pressupostos do Comitê de Ética em Pesquisa, uma vez que a pesquisa foi devidamente aprovada pelo mesmo, na UDESC.

As entrevistas com os pais das crianças foram realizadas também nas escolas. Apenas três

deles foram entrevistados em seus locais de trabalho, pela dificuldade de comparecer à escola.

Após a coleta de dados, os mesmos passaram por análise, seguindo-se os pressupostos do método da Análise de Conteúdo, segundo Bardin (1977).

\section{APRESENTAÇÃO, ANÁLISE E INTERPRETAÇÃO DOS DADOS}

$\mathrm{Na}$ análise do material, tanto dos professores, quanto dos alunos, diferentes categorias de análise emergiram, sendo que, neste artigo será apresentada a análise da categoria 
denominada como:

\section{Imagens, Interação Social e Aprendizagens na Escola Inclusiva}

Os dados dos professores são reveladores de preocupações com a formação, em duas direções: uma, que se relaciona com novos domínios, teorias e tecnologias, com questões legislativas e curriculares.Outra, com a dificuldade ainda existente para a aceitação de diferenças entre as crianças, particularmente relacionadas com ritmos distintos de aprendizagem na mesma sala de aula.Há preocupação, por parte dos professores, com a distância da sociedade e de de muitas famílias , da escola.

Ao escrever para um professor que tenha sido significativo na trajetória profissional manifestaram-se insights importantes para a compreensão de contextos em mudança. Esses insights referem-se a uma tensão crescente entre duas posições que possuem potencial fortalecedor e persuasivo na luta contra a opressão e na busca pela liberdade humana, essenciais quando se fala em educação inclusiva. Duas questões foram presentes na maioria dos professores: como é possível eliminar o sofrimento das crianças com necessidades educativas especiais e de suas famílias? Como sensibilizar a sociedade, as autoridades responsáveis pelas políticas públicas para pensar sobre esse sofrimento que exclui, segrega, aprisiona e conduz à alienação social ?

Alguns evidenciaram sentir medo diante desses desafios, insegurança, relacionando-os com a própria formação, que consideraram insatisfatória para trabalhar com as diferenças em uma mesma sala de aula.Revelaram que, em alguns momentos consideram que seria melhor manter o modelo anterior,pelo temor de que a educação inclusiva não alcance os resultados propostos.Encontram-se presos a um modelo de educação que não coincide com as demandas atuais e, por essa razão preferem manter um modelo pedagógico já solidificado e, segundo seu ponto de vista, consolidado pelo tempo.Trata-se de duas posições distintas, mas que coexistem nas escolas com educação inclusiva.

Os desenhos realizados pelas crianças com necessidades educativas especiais que foram participantes da pesquisa estão associados com o que as mesmas conhecem, bem como com a imaginação.Para Vygotsky, a imaginação é uma atividade vinculada com a realidade e com o significado.Pelos desenhos, as crianças interpretam o mundo, mostram o que conhecem, interpretam a realidade.Pelas verbalizações associadas aos desenhos, as crianças atribuem significados aos mesmos.Esses significados revelam o sentido atribuído ao 
desenho pela própria criança.Não se trata então, de uma interpretação que parte de uma outra pessoa, mas que é atribuída pela própria pessoa que desenha.O pensamento expresso pela palavra da criança explicita seu mundo.Os desenhos por si mesmos, sem as verbalizações não explicitam os significados que a criança atribui ao que faz.A criança desenha o que conhece, mas faz desconstruções, reconstruções em novas combinações, de acordo com suas experiências, imaginação e ações criativas.Assim, concorda-se com Vygotsky (2003), quando refere que a experiência da criança deve ser ampliada, para proporcionar uma base sólida à atividade criativa.Quanto mais a criança aprende,quanto maiores e expressivas forem suas experiências, mais capaz será de processar diferentes aprendizagens.Nessa perspectiva, a escola representa um papel importante.A capacidade imaginativa se amplia pela experiência.É na relação com os outros, com o meio, com a cultura que a imaginação se manifesta e,simultaneamente amplia o repertório imagético.Nesse processo, a criança passa a ampliar a consciência de si, sua auto-confiança se amplia, e a linguagem assume um papel mediador pelos signos verbais.Algumas crianças com necessidades educativas especiais, participantes da pesquisa expressaram-se também pelos movimentos corporais e por sinais, que constituíram então,signos para a comunicação de significados.Na realidade, na perspectiva de Vygotsky $(1987 ; 2003)$ a riqueza expressiva ocorre pela via da linguagem que, associada à imagem possibilita o acesso ao significado.Por essa razão, nessa perspectiva não se interpreta o traçado do desenho, os esquemas gráficos, mas uma totalidade, que dá sentido ao processo vivenciado pelos sujeitos.A análise dos desenhos, segundo a teoria de Vygotsky, integra imagem e palavra,e está na gênese da construção da categoria de sentido.A escola inclusiva tem um papel que se relaciona com o processo de compreensão da constituição do desenho: ninguém desenha o que vê, segundo Vygotsky (2003), mas o que aprende a ver.Na série de desenhos realizada pelas crianças foi possível evidenciar a presence gradativa de elementos, objetos do meio, bem como vivências interativas. $\grave{A}$ medida em que desenhavam,acionavam processos criativos, imaginativos e interativos.Concorda-se com Vygotsky (2001;2003), ao referir que existe uma associação íntima entre imaginação, criatividade, desenho e aprendizagem.Essas questões devem permear o cotidiano da escola que se afirma inclusiva.O desenho é importante no processo educativo, no desenvolvimento e aprendizagem da criança, permitindo a ampliação de repertórios de conhecimento que, por sua vez, permitem que o imaginário se expresse em 
novas combinações e aprendizagens.

Uma criança participante da pesquisa fez desenhos com caneta coloridas, acrescentando verbalizações. Trata-se de um menino com transtorno por déficit de atenção com hiperatividade, que viu seu pai assassinado, em frente de sua casa.Seus desenhos estão associados com o que viu.Os primeiros desenhos expressaram essa questão da morte do pai.Aos poucos, em novos encontros, passou a desenhar objetos do cotidiano ( o travesseiro triste, o bolo triste). Em outro desenho mostrou crianças felizes (crianças sorvete), valorizando a interação,manifestando novas combinações da imaginação, associadas à interação social.No último desenho aparece a fantasia,que Vygotsky (2003) vincula com a imaginação ,associadas ao desejo de ter um tênis com luzes coloridas,para escorregar para lugares mais felizes.O desenho dessa criança, acrescido das verbalizações possibilitou o acesso a diferentes significados, e à construção de um sentido para a escola inclusiva, que é o de possibilitar a interação e, através dela imaginar, apreender novas realidades.

Derdik (2003) refere que a criança é capaz de reter na memória grande quantidade de informação visual e, pela atividade mental, é capaz de associar, combinar, sintetizar, nomear, presentificando a associação entre mão, olho e cérebro, que se evidencia nas ações de desenhar.

As premissas da obra de Vygotsky podem ser evidenciadas nos desenhos das crianças, nas suas verbalizações, bem como nas dos professores: o processo de aquisição do conhecimento é uma construção, que se dá em interação social.Nessa dinâmica estão incluídas as funções psicológicas superiores tipicamente humanas. Pelas visualidades, a criança revela figurações, fantasias e o imaginário.Essas representam a realidade, as vivências da criança, sendo socialmente constituídas.A associação do desenho com a palavra constitui a questão central da pesquisa: a auto-atribuição de significados. De acordo com o material coletado, diferentes sentidos ficaram evidentes na pesquisa: a importância da interação social na escola com educação inclusiva, a oportunidade de aprender integrando percepções,imaginação,memória, que permite a ação das representações mentais; a importância dos contextos referenciais nas trajetórias dos professores,definindo tipos de vínculos com a educação inclusiva.As premissas da obra de Vygotsky podem ser evidenciadas nos desenhos das crianças, nas suas verbalizações, bem como nas dos professores: o processo de aquisição do conhecimento é uma construção, que se dá em 
interação social.Nessa dinâmica estão incluídas as funções psicológicas superiores tipicamente humanas,tais como a memória, a percepção, a imaginação, as representações mentais.

\section{CONSIDERAÇÕES FINAIS}

A análise dos dados permite considerar que, apesar de constituir-se em um processo inovador, que exige tolerância para com as diferenças, mobilização para novas atualizações por parte dos professores, um dos sentidos da educação inclusiva insere-se na perspectiva de construção de uma sociedade que convive com a diversidade.As imagens, as verbalizações dos professores participantes da pesquisa assinalam para esse sentido.Não se trata de uma visão única, mas mostrou-se presente na produção da maioria.Quanto às crianças com necessidades educativas especiais, a educação inclusiva adquire um sentido que focaliza a interação social como bem maior a ser cultivado; o estímulo às manifestações do imaginário, pela via do desenho, vinculado aos processos perceptivos adquire sentido quando associado à construção do conhecimento, na visão que integra infância e produção cultural, com aceitação incondicional das diferenças entre as pessoas. Trata-se de um campo no qual a arte ocupa um espaço importante; o campo da arte é um espaço aberto, e aberto para todos, assim como é o cenário da educação inclusiva. As premissas da obra de Vygotsky podem ser evidenciadas nos desenhos das crianças, nas suas verbalizações, bem como nas dos professores: o processo de aquisição do conhecimento é uma construção, que se dá em interação social.Nessa dinâmica estão incluídas as funções psicológicas superiores tipicamente humanas,tais como a memória, a percepção, a imaginação, as representações mentais.

\section{REFERÊNCIAS BIBLIOGRÁFICAS}

BARDIN, Lawrence. Análise de Conteúdo. Lisboa: Edições 70, 1977.

Alegre: Artes Médicas, 1995.

BERIAIN, Juan. Lãs Consecuencias Perversas de la Modernidad. Barcelona: Antrophos, 1996. 
DERDYK,Edith. Formas de Pensar o Desenho. São Paulo:Scipione, 2003.

McLAREN,Peter.Multiculturalismo Crítico. São Paulo:Cortez, 1997.

OLIVEIRA,Marta K. Vygotsky: Aprendizado e Desenvolvimento -O Processo Sócio-

Histórico.São Paulo: Scipione, 2001

SKLIAR, Carlos. E se o Outro não Estivesse aí?Notas para uma Pedagogia (Improvável)

da Diferença.Rio de Janeiro:DP\&A, 2003.

VYGOTSKY, Lew.S. Psicologia Pedagógica. São Paulo: Martins Fontes, 1984..

VYGOTSKY,Lew S.A Formação Social da Mente. São Paulo: Martins Fontes, 1987.

VYGOTSKY, Lew.S. A Psicologia da Arte. São Paulo: Martins Fontes, 2001

VYGOTSKY,Lew. S. La Imaginación y la Arte en la Infancia. Espanha: Akal, 2003. 